\title{
New frontiers and future \\ directions in interactive marketing: Inaugural Editorial

\section{Introduction}

Since interactive marketing evolved from a traditional form of direct marketing and e-commerce around three decades ago (Deighton, 1996), it has grown dramatically to be the fastest developing business field with mobile applications and interactive content. While the term interactive marketing often has diverse definitions and usages among marketing professionals and practitioners, it is defined here as the bi-directional value creation and mutual-influence marketing process through active customer connection, engagement, participation and interaction. Such a definition characterizes interactive marketing in terms of the following aspects, namely, first, it is a two-way communication with mutual influences in social and business ecosystems; second, it focuses on customer responsiveness and often proactive behaviors in value creation and exchange; and third, its interactivity involves customer participation and engagement in controlling and modifying the environment in real-time (Steuer, 1992).

The advent of interactive marketing has been accompanied by the declining influence of passive broadcast advertising and one-way persuasive communication. Contemporary interactive marketing has also moved beyond the scope of direct marketing, as the market is becoming a forum for conversations and interactions among connected actors or participants via digital and mobile activities in platform ecosystems. The increasing use of artificial intelligence (AI), virtual reality (VR) or augmented reality (AR) further facilitates marketers to deliver convenience, personalized content and exceptional experiences.

\section{Major driving forces that reshape interactive marketing}

The booming of interactive marketing echoes the rapid development and innovation in new technologies, platform revolution, participating culture and social media proliferation. Everything from VR simulations, chatbots, voice-activated content, interactive short video and live streaming to mobile and messaging apps, interactivity has become an integral part of contemporary marketing practice. When combined with social media, interactive marketing is particularly effective in developing a more tailored and personalized approach that allows customers to dive in and enjoy the interactive process on a deeper level.

Technology advancement fuels the growth of interactive marketing with powerful tools. Interactive marketing, which emerged at the beginning stage of the digital edge and e-commerce, has dramatically expanded its scale and scope because of the newly developed and more sophisticated technologies. In particular, AI, VR and AR have largely reshaped consumerbrand interactive relations and enhanced shopping experience with portable and embodied devices and highly interactive virtual connections (Flavián, Ibáñez-Sánchez and Orús, 2019). The integration of physical and virtual objects allows consumers to experience the product in the digital landscape via virtual fitting rooms or bring the digital world to physical stores where shoppers can experience every facet of the brand through immersive multimedia content. The application of big data and social recommender system increases more focused and personalized marketing activities in content recommendation, from referring a friend to recommending a handbag or generating playlists for music or video service. Chatbots, as

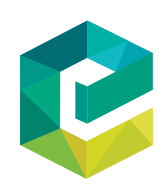


JRIM

15,1

2

conversational agents, enable customer direct online interaction with simulated dialog and customer support live chat service and fast responses via web-based applications or standalone apps. Beacon technology becomes a proximity-marketing tool that helps companies in making location-based searching and interaction, improving mobile visibility and customer engagement and monitoring the effectiveness of digital advertising that drives customers and sales to retailing stores.

Platform revolution is forming a new business ecosystem for customer connections and interactivities. The growth of digital platforms has displaced traditional intermedia not only by creating a new type of superpower of omnichannel marketplace spanning online and offline retailers but also changed business models from a linear supply chain pipeline to a complex network of producers and users in an interconnected ecosystem (Parker, VA Alstyne and Choudary, 2016). Through enhanced network effect, the platform features an infrastructure that brings external sellers and buyers together, regardless of sources through data-driven matchmaking. The process of value creation is vigorously shifting from the product- and firm-centric view to personalized and interactive customer experience. Brand platforms provide a channel of direct consumer-brand interaction that allows consumers to surf in their favorite shopping websites to discover the hottest new trends and receive real-time customized recommendations. Social network platforms establish hubs of brand communities that congregate users who contribute to newsfeeds and share brand information by tagging friends. Media sharing platforms create opportunities for both marketers and users to spread brand-related information via mobile marketing. Content-sharing communities in fandom platforms established in Facebook and Baidu are promoting interactions between net celebrities and fans through storytelling and ritualistic practice in virtual brand communities. The "watching and purchasing" function in many short video and live streaming platforms facilitates instant selling through host and audience interaction.

Advent of participatory culture and fandom community facilitates customer engagement. Participatory culture, enabled by web technology, provides individuals new forms of expression and engagement in public discourse, acting as contributors or producers rather than as passive consumers (Jenkins et al., 2006). Fan culture and fandom behavior have particularly changed the consumer-brand relationship in such a way that consumers take more active and enthusiastic roles as prosumers and brand evangelists by creating brandrelated content in newsfeeds and blogs or promoting and selling a brand in embedded advertising, influencer marketing and live streaming (Wang, 2020). User-generated content (UGC) is particularly effective, allowing users to create and publish media content and achieve considerable reach through dynamic social networks (Ho, Pang and Choy, 2020). Considering that social network sites enable users to gather information and share opinions, consumers are no longer passive recipients of brand information but are active generators and distributors of such information through social recommendations. Fans from brand communities act as prosumers, who play vital roles in brand co-production, creation, promotion and distribution through interactive conversations and dialogues among fan cultural groups and brand communities, consequently attracting other participants and accelerating market expansion (Humphrey, Laverie and Shields, 2018).

Proliferation of social media shifts marketing to a truly interactive era. The omnipresence of social-media inspirational content in contemporary life, encompassing a wide range of websites and mobile apps, inspires users to quickly create and share content with friend circles and the public in real-time (Izogo and Mpinganjira, 2020). Social media dramatically altered the dynamics of consumer involvement in interactive marketing by providing shopping options and shoppable posts via external links. Interactivity is becoming the core feature of social media platforms, and nearly all have built-in interactive capability that users can interact with 
marketers and other users in a multi-sided or triad relationship. Social media apps encourage users' engagement and making recommendations, strengthening consumer-brand relationships through branded storytelling (Lim and Childs, 2020). For instance, simply by clicking at a mobile device, users can "like" or forward a post; can @ or add or tag friends for a particular content or brand information; can "follow" a blogger to build a fan base or use hashtag for the cross-referencing of content sharing a theme; can express and share feelings via emojis. The audience can further interact with hosts or streamers through instant comments via "screen barrage" (real-time comment function floating above the video) to build synchronicity or by online tipping (sending gifts or money as gratuity) to give a reward on interactive short videos or live streaming.

\section{Changing landscape of interact marketing}

The traditional broadcast advertising and one-way mass media communication has given way to two-way interaction with enhanced consumer-brand relationship. Spearheaded by industry-wide marketing practices under various interactive innovations, the past three decades have witnessed significant changes in the interactive marketing landscape, displaying major shifts in the following realms:

From person-to-person direct selling toward platform-orchestrated multi-sided network interactions. Marketing in the platform ecosystem becomes increasingly interactive as the role of seller and buyer or producer and consumer is blurring. Digital platforms increase the exchanges in a global scope without physical or distance restriction, as the market is becoming a forum for conversations and interactions among connected global actors. Users in various social media platforms diverse in terms of goals (i.e. for informational, social and enjoyment purposes) and brand co-creation (Pelletier, Krallman, Adams and Hancock, 2020). Platforms effectively match producers/providers and consumers/users in a multi-sided marketplace through network interactivity. Consequently, participants can swap their roles from hosts to customers on Airbnb, from drivers to riders on Uber and Didi, from media content creators to audience on Youtube and Wikipedia. The emergence of lifestyle platforms with super apps provides consumers a one-stop shopping experience and enables the latter to obtain the desired product in just one click. For example, Meituan Dianping, a Chinese group buying website for locally found food delivery services, has expanded to more than 30 services from restaurant reviews, reservations, movie tickets, home rentals, hotel bookings to travel booking and grocery ordering. Alipay has also evolved from a payment app to hosting more than 200,000 mini-programs, including those that enable users to manage their healthcare, investments, invoices, car payments and insurance.

From campaign-based broadcasting toward organic marketing that engages customer seamless shopping experience. As social media content is merging with online shopping, consumers integrate browsing, exploring and sharing with different forms of content. Social network platforms thus, make marketing "organic" by transforming marketing activities to consumer daily life events when consumers are using mobile apps to read news, share photos, express opinions, visit websites and play games. An organic marketing strategy, which integrates shopping and daily routine on mobile times, generates traffic and selling naturally with a little push from tweets, blog or Weibo posts, Facebook timelines or WeChat moments. Consumers' shopping journey thus, takes an alternate form as unplanned and incidental shopping when they are promoted to discover, shop and purchase during their mobile times on reading, chatting, entertaining and streaming. Meanwhile, marketers can take social media actions that are evoked and executed in real-time proximal to an external event through improvised marketing interventions (Borah, et al., 2020). Consequently, 
JRIM

15,1

marketing is truly interactive and organic, while selling and buying are becoming a naturally generated byproduct.

From customer response programs toward gamification and entertaining activities. In the interactive marketing landscape, marketing can be fun, exciting and inviting, with more active customer participation and engagement. Gamification of marketing introduces elements of game playing, such as rules of play, contests, rewarding programs, point scoring and competition with others, into marketing content to encourage customer engagement with a product or service. For example, Bally's emoji contest in WeChat encourages its participants to choose a product while being creative and imaginative by making emojis or browsing and voting for their favorite emojis created by other users. Similarly, Michael Kors launched a video competition on WeChat in collaboration with the FaceU app (an AR selfie camera app) in China. Uploading short videos with Michael Kors' theme on social media for a chance to win a handbag or a bottle of Michael Kors' perfume excites users with a fun and rewarding experience.

Buzz can be also generated through entertaining events that attract customers to interact with the brand and make referrals to other users. For example, Pepsi's global campaign interacts with consumers using Pepsi's own version of the emoji. It creates an experiential "universal language" of free downloadable PepsiMoji keyboard for mobile phones, inviting consumers worldwide to share their favorite emojis with the hashtag \#sayitwithpepsi in their social media posts or selfies. While enjoying emoji-clad bottles and cans, consumers have the opportunity to directly interact with the brand and other consumers through "say it with Pepsi" conversation via regionally specific emoji designs, videos and a built-in photo booth.

From basic online communications toward virtual reality-supported omnichannel shopping experience with the synchronization of digital and physical worlds. Omnichannel marketing, together with AV technologies, integrates online and offline activities and enhances seamless shopping and selling experience at the right place and time. Retail customer interaction has been changing from a traditional way of visiting storefronts to shopping at home via e-commerce and now to omnichannel. Marketers create integrated customer experiences spanning both online and offline channels through all potential touchpoints that customers can use to communicate with brands. The interactivity is beyond marketer and customer but expanding to customerbrand interaction via AR technologies. For example, the AR application allows users to test IKEA's products in real-time featuring realistically rendered true-to-scale three-dimensional products based on room dimensions. Alibaba is applying VR to transport shoppers into virtual malls. Tmall has made a smart mirror app that allows users to apply up to 2,000 makeup shades from various brands, and users can instantaneously share photos with friends for comments. Burberry brings the digital world to life in a physical space to allow customers to experience every facet of the brand through immersive multimedia content exactly as they do online.

From e-commerce toward social commerce and customer-generated marketing. The wide application of social media and mobile apps expanded social networks via virtual interaction. Socializing and sharing is an intrinsic need of social media users who will gain a greater sense of belonging and participation than they will typically gain from simply shopping around from one website to another. The marketplace for e-commerce has extended to social network sites in which users exchange and share their interests and experiences through social selling and user-generated marketing activities. In particular, social e-commerce, empowered by a social recommender system with personalized techniques to present the most relevant product information, actively stimulates demand through social activities (Handarkho, 2020) and social selling (Niedermeier, 2020). Social selling and social shopping are inherently to be interactive through user-get-user activities in daily life. For instance, the success of Pingduoduo, a Chinese social e-commerce platform, is largely derived from customer-generated shopping experience through online social 
network sites. The group purchase model via interactive user-get-user referrals, differing from firm-centered referral programs used by many companies, enhances shopping experience through consumer network connections and user-generated marketing. Group buying participants are rewarded when they reach the targeted number of buyers to qualify for the discounted price through customer recruiting activities.

From celebrity endorsement toward micro-influencer marketing by ordinary participants via live streaming marketing. The popularity of live streaming and short-video marketing has reshaped the traditional communication model that is based on the trickle-down effect, in which elites or celebrities pose a remarkable influence on mass market behavior. The overwhelmingly increasing numbers of net celebrities and live streamers in social network platforms lead to the democratization of KOLs, who can be ordinary people such as bloggers or users of short videos with a sizable proportion of followers. Compared with traditional celebrity endorsement by movie or athletic stars with higher social status, micro influencers or KOLs from ordinary people are more close to the life of an average consumer and capable of becoming more interactive with followers and potential consumers (Al-Emadi and Ben Yahia, 2020). Such real life influencers from the grassroots, who are product innovators and passionate about the recommended products, not only have a significant following but a relatively higher number of buying conversations because consumers are likely to trust and act on a UGC (Akdevelioglu and Kara, 2020). The buying-while-watching function in social media or live streaming platforms let viewers instantly add goods to the shopping cart in interactive live streaming.

From banner advertising and search engine marketing toward proximity marketing and mobile marketing. The advancement of interactive technology is moving from navigating the environment to becoming capable of monitoring and modifying the environment (Flavián et al., 2019). Consequently, interactive marketing has been moving beyond trafficgenerating internet marketing strategies through banner advertising and search engine marketing, thereby enabling marketers to engage the customer at the right place and time. The development of proximity technologies, such as Beacons, allows marketers to identify, locate and connect with consumers nearby through smart devices, enhancing marketer and customer real-time responsiveness. The proximity marketing becomes a more focused and targeted strategy to trigger promotion events to nearby consumers by delivering other relevant information, making customized product recommendations and providing instant shopping incentives. As the time spent on smartphone in everyday life is dramatically increasing, traditional internet marketing is evolving into more personalized and interactive mobile marketing via location-based apps.

From word-of-mouth viral marketing toward word-of-click and shoppable posts via user-generated content marketing UGC has been extensively used in content marketing in the participant culture as brand users and fans create and share their brand experience. Social media users exchange thoughts and information by news feeds, articles, photos and short videos in blogs or posts (Xue, 2019). UGC campaigns put passion, knowledge and artistic talent on display for others to see and enjoy. Because of the high speed and wide reach of social media, the traditional viral marketing through word-of-mouth is becoming more efficient word-of-click when users contribute to newsfeed and followers recommend posts with a quick click or even with a "like" emoji in their mobile devices. Given that UGC is perceived as more authentic and honest, marketers often share brand-related UGC on their own social media accounts, website and other marketing channels. The expanded social networks consequently create new opportunities for marketers to co-opt the power of promoting brands via sponsored social recommendations by paying high influential bloggers or KOLs to contribute brand-related posts or tweets. The UGC becomes sponsored UGC in content marketing.

Inaugural Editorial 
JRIM

15,1

6

Considering that the UGC tagged with products or brands allows users to shop instantly, social media platforms provide users with built-in tools to monetize feeds as shoppable posts. Shoppable content, including articles, images or photos and videos, emerges as a shopping venue through the integration of content with mobile marketing and embedded advertising. When consumers come across brand-related images or video content arousing shopping interest, they can instantly buy the product using the built-in product tagging feature and buying option. Social media visitors or blog followers are, thus directly converted into buyers through shoppable posts, skipping the inconvenient shopping journey that typically separates browsing and shopping experience or information search and buying tasks. This process then reduces the risk of abandoning purchasing action during the task switching.

From business-initiated marketing toward dynamic two-way interaction and customer-brand co-building. Technological thrust in big data and AI further reshapes marketing by prioritizing consumers' needs. The increasing consumer participation and engagement in marketing lead to consumer-to-business (C2B) innovation, allowing customers to add value to the company by harnessing their insights. The $\mathrm{C} 2 \mathrm{~B}$ model connects end-producers and end-consumers to produce tailored products using data insight and following trends. Meanwhile, consumers take a more active role in influencing production, communication and distribution and as in the case of Pinduoduo's pricing strategies. Pinduoduo shares consumer data with retailers and producers, allowing them to better understand market demand, consumer needs and budget. When potential buyers spot a deal on Pinduoduo, they can directly share a link to the item with their friend circles in social platforms to obtain the desired product at the desired price.

The increasing influence of consumer fandom on prosumer marketing has facilitated consumer-brand interaction and brand co-building. Brand fans act as brand evangelists to enthusiastically recommend the brand to other fans in the physical and virtual brand community (Wang, Sarkar and Sarkar, 2018, 2019). Fans engage in creative activities, including the creation of written works, visual or computer-assisted art, music or applied arts and costuming. As consumer brand identification enhances the strength of the consumer-brand relationship (Graham and Wilder, 2020), consumers often post selfies featuring their favorite brands, particularly those conspicuous luxury brands, to express their symbolic self or showcase their lifestyle and their social belonging (Huang and Wang, 2018).

The fast growing game industry and thriving game consumption market witnessed the growth of professional gamers and online game live streamers, who engage in both production and consumption processes in the cyber world of game fandom. Game streamers, sponsored by game developers, often become self-willing fan labors, who test new games in exchange for early access or promotional merchandise (Stanfill and Condis, 2014). Livestreaming media are particularly effective in creating fandom through interactive multimedia communications by paying top game players who invite followers to watch them playing at game-streaming sites. Consumer-brand relation is enhanced in the interaction process via social media content-consumption and content-contribution (Qin, 2020).

Future research direction of interactive marketing: updated aim and scope for JRIM

Interactive marketing, in its varying forms as digital marketing, mobile marketing and social media marketing, provides customers with dynamic, engaging and relevant content via personalized live streaming, interactive video and gamified platforms. The built-in interactive feature of social media transforms marketing into consumer life 
events and an integrated experience of communicating, socializing, posting or sharing in newsfeed, reading online content, playing games or watching videos, surfing the web, shopping and paying products. The future of interactive marketing will maintain the forward momentum, capitalizing the technological advancement and application in social media and mobile marketing with more personalized and dynamic content. While keeping the continuity of the long-standing aims to publish progressive, innovative and rigorous scholarly research for marketing academics and practitioners, the future of IJIM will advance theoretical conceptualization and managerial relevance to the interactive marketing research field. Authors are encouraged to submit manuscripts demonstrating cutting-edge thinking in interactive marketing from multidiscipline perspectives (e.g. AI and information system, sociology, psychology and social media) with practical relevance to emerging marketing applied fields. However, all submissions to JRIM for publication consideration must have a focus on interactive marketing domains or from an interactive marketing perspective. The updated aims and scope of JRIM reflect the advanced technologies and industrial practices in the following areas:

- Investigating customer behaviors and interactivities in social media networks and varying electronic platforms.

- Applying newly developed technologies (AI, VR and AR, networking and recommendation systems and mobile apps) in interactive marketing.

- Harnessing the power of consumer engagement, UGC, live streaming and influencer marketing.

- Looking into interactive marketing experience in online, multichannel and omnichannel activities.

- Examining effective omnichannel interactive marketing activities across different markets and countries.

- Inspecting the influence of interactive features of social media and mobile apps on customer engagement and experience.

- Measuring and evaluating the effectiveness of interactive marketing across varying business practices and activities.

- Identifying and exploring emerging issues and newly developed applications associated with the rapidly expanding field of interactive marketing.

- Scrutinizing the potential dark side of applying interactive and personalized technologies that influence privacy, security and consumerism.

\section{Cheng Lu Wang \\ Department of Marketing, College of Business, University of New Haven, West Haven, Connecticut, USA}

\section{References}

Akdevelioglu, D. and Kara, S. (2020), "An international investigation of opinion leadership and social media", Journal of Research in Interactive Marketing, Vol. 14 No. 1, doi: 10.1108/JRIM-11-2018-0155.

Al-Emadi, F.A. and Ben Yahia, I. (2020), "Ordinary celebrities related criteria to harvest fame and influence on social media", Journal of Research in Interactive Marketing, Vol. 14 No. 2, pp. 195-213, doi: 10.1108/JRIM-02-2018-0031. 
JRIM

15,1

8

Borah, A., Banerjee, S., Lin, Y., Jain, A. and Eisingerich, A.B. (2020), Journal of Marketing, Vol. 84 No. 2, pp. 69-91.

Deighton, J.A. (1996), “The future of interactive marketing”, Harvard Business Review, Vol. 74 No. 6, pp. 151-160, available at: www.hbs.edu/faculty/Pages/item.aspx?num=7213

Flavián, C., Ibáñez-Sánchez, S. and Orús, C. (2019), "The impact of virtual, augmented and mixed reality technologies on the customer experience", Journal of Business Research, Vol. 100, pp. 547-560, available at: www.sciencedirect.com/science/article/pii/S0148296318305319

Graham, K.W. and Wilder, K.M. (2020), "Consumer-brand identity and online advertising message elaboration: effect on attitudes, purchase intent and willingness to share", Journal of Research in Interactive Marketing, Vol. 14 No. 1, pp. 111-132, doi: 10.1108/JRIM-01-2019-0011.

Handarkho, Y.D. (2020), "The intentions to use social commerce from social, technology, and personal trait perspectives: analysis of direct, indirect, and moderating effects", Journal of Research in Interactive Marketing, Vol. 14 No. 3, pp. 305-336, doi: 10.1108/JRIM-10-2018-0137.

Ho, J., Pang, C. and Choy, C. (2020), "Content marketing capability building: a conceptual framework", Journal of Research in Interactive Marketing, Vol. 14 No. 1, pp. 133-151, doi: 10.1108/JRIM-062018-0082.

Huang, Z. and Wang, C.L. (2018), "Conspicuous consumption in emerging market: the case of chinese migrant workers", Journal of Business Research, Vol. 86, pp. 366-373, doi: 10.1016/j. jbusres.2017.08.010.

Humphrey, W.F., Laverie, D.A. and Shields, A.B. (2018), "Building the force: enacting fan brand community through the star wars BB-8 droid builders club", in Wang, C.L. (Ed.), Exploring the Rise of Fandom in Contemporary Consumer Culture, IGI Global Inc., Hershey, PA, pp. 126-146, available at: www.igi-global.com/chapter/building-the-force/190236

Jenkins, H., Clinton, K., Puroshotma, R., Robinson, A. and Weigel, M. (2006), "Confronting the challenges of participatory culture: media education for the 21st century", The MacArthur Foundation, available at: www.macfound.org/media/article_pdfs/JENKINS_WHITE_PAPER. PDF

Izogo, E.E. and Mpinganjira, M. (2020), "Behavioral consequences of customer inspiration: the role of social media inspirational content and cultural orientation", Journal of Research in Interactive Marketing, Vol. 14 No. 4, pp. 431-459, doi: 10.1108/JRIM-09-2019-0145.

Lim, H. and Childs, M. (2020), "Visual storytelling on Instagram: branded photo narrative and the role of telepresence”, Journal of Research in Interactive Marketing, Vol. 14 No. 1, pp. 33-50, doi: 10.1108/JRIM-09-2018-0115.

Niedermeier, K.E. (2020), "A conceptual framework for understanding the antecedents and consequences of social selling: a theoretical perspective and research agenda", Journal of Research in Interactive Marketing, doi: 10.1108/JRIM-05-2020-0108.

Parker, G.G., Van Alstyne, M.W. and Choudary, S.P. (2016), "Platform revolution: how networked are transforming the economy - and how to make them work for you", W.W. Norton and Co., New York, NY, available at: wwnorton.com/books/Platform-Revolution

Pelletier, M.J., Krallman, A., Adams, F.G. and Hancock, T. (2020), "One size doesn’t fit all: a uses and gratifications analysis of social media platforms", Journal of Research in Interactive Marketing, Vol. 14 No. 2, pp. 269-284, doi: 10.1108/JRIM-10-2019-0159.

Qin, Y.S. (2020), "Fostering brand-consumer interactions in social media: the role of social media uses and gratifications", Journal of Research in Interactive Marketing, Vol. 14 No. 3, pp. 337-354, doi: 10.1108/JRIM-08-2019-0138.

Stanfill, M. and Condis, M. (2014), "Fandom and/as labor, (editorial)", in Stanfill and Megan (Eds), Special Issue, Transformative Works and Cultures, No. 15, doi: 10.3983/twc.2014.0593

Steuer, J. (1992), "Defining virtual reality: dimensions determining telepresence", Journal of Communication, Vol. 42 No. 4, pp. 73-93, doi: 10.1111/j.1460-2466.1992.tb00812.x. 
Wang, C.L. (2020), "Contemporary perspectives on fandom research: an introduction”, in Wang, C.L. (Ed.), Handbook of Research on the Impact of Fandom in Society and Consumerism, IGI Global Inc., Hershey, PA, available at: www.igi-global.com/book/handbook-research-impact-fandomsociety/230951

Wang, C.L., Sarkar, A. and Sarkar, J.G. (2018), "Building the holy brand: towards a theoretical model of brand religiosity", International Journal of Consumer Studies, Vol. 42 No. 6, pp. 736-743, available at: https://onlinelibrary.wiley.com/doi/abs/10.1111/ijcs.12430

Wang, C.L., Sarkar, J.G. and Sarkar, A. (2019), "Hallowed be thy brand: measuring perceived brand Editorial emerald.com/insight/content/doi/10.1108/EJM-08-2017-0551/full/html

Xue, F. (2019), "Facebook news feed ads: a social impact theory perspective", Journal of Research in Interactive Marketing, Vol. 13 No. 4, pp. 529-546, doi: 10.1108/JRIM-10-2018-0125.

\section{Further reading}

Florenthal, B. (2019), "Young consumers' motivational drivers of brand engagement behavior on social media sites: a synthesized U\&G and TAM framework", Journal of Research in Interactive Marketing, Vol. 13 No. 3, pp. 351-391, doi: 10.1108/JRIM-05-2018-0064. 